Association for Information Systems AIS Electronic Library (AISeL)

SIGHCI 2007 Proceedings

Special Interest Group on Human-Computer

Interaction

2007

\title{
Online Trust and Health Information Websites
}

Cynthia L. Corritore

CreightonUniversity, cindy@creighton.edu

Susan Wiedenbeck

Drexel University, sw53@drexel.edu

Beverly Kracher

Creighton University, beverlyk@creighton.edu

Robert P. Marble

CreightonUniversity,marble@creighton.edu

Follow this and additional works at: http://aisel.aisnet.org/sighci2007

\section{Recommended Citation}

Corritore, Cynthia L.; Wiedenbeck, Susan; Kracher, Beverly; and Marble, Robert P., "Online Trust and Health Information Websites" (2007). SIGHCI 2007 Proceedings. 20.

http://aisel.aisnet.org/sighci2007/20

This material is brought to you by the Special Interest Group on Human-Computer Interaction at AIS Electronic Library (AISeL). It has been accepted for inclusion in SIGHCI 2007 Proceedings by an authorized administrator of AIS Electronic Library (AISeL). For more information, please contact elibrary@aisnet.org. 


\section{Online Trust and Health Information Websites}

\author{
Cynthia L. Corritore \\ Creighton University \\ cindy@ creighton.edu
}

\author{
Susan Wiedenbeck \\ Drexel University \\ sw53@drexel.edu
}

\author{
Beverly Kracher \\ Creighton University \\ beverlyk@creighton.edu
}

\author{
Robert P. Marble \\ Creighton University \\ marble@creighton.edu
}

\begin{abstract}
This study develops and tests a model of online trust of a health care website. The model showed a statistically strong fit to the data $(\mathrm{N}=176)$. Trust was significantly explained by perceptions of credibility, ease of use, and risk. Perceived ease of use was a direct predictor of trust and an indirect predictor through credibility. Credibility was both a direct predictor of trust and an indirect predictor through risk.
\end{abstract}

\section{Keywords}

Trust, health care websites, risk, credibility, PEOU.

\section{INTRODUCTION}

One of the most important elements of health care success is trust between the health care provider and those seeking health care. But what happens to trust when health information goes online? The use of the Internet for obtaining health information has grown to 80 percent, or about 113 million, in 2006 (Madden \& Fox, 2006). Millions each day consult the Internet for health wellness information, such as descriptions of healthy diets and exercise (Madden \& Fox, 2006). As the Internet increasingly supplements, or even supplants, health care providers as primary sources of well health information for users, an open question is whether users will accept the information they read on health websites. It seems clear that, in order for online health information to be effective, users must have trust in informational health websites. Yet little empirical research has been done to date on this trust. We seek to identify factors that affect users' trust in well health information websites, as well as a way to measure these factors. Knowledge gained from this study may ultimately be used to build health information websites that facilitate user trust, so that online well health websites will be an effective tool in promoting user health.

This study examines online trust and three antecedents to trust in the context of health wellness information websites for well young adults. The purpose of the study is to 1) develop better measures for predicting and explaining online trust of well health websites, and 2) evaluate a model of online trust in the context of a well health information website.

\section{LITERATURE REVIEW}

The importance of trust between patients and health care providers in traditional settings has long been associated with successful outcomes, improved patient satisfaction, and increased patient participation, or empowerment, in their own health care. However, due to the limited research about the nature of trust of health information websites, research findings from non-healthcare websites were also examined.

Researchers have posited a relationship between ease of use and online trust (Corritore et. al., 2003) of non-health websites. Associations between increased online trust and ease of searching, ease of transacting, and ease of navigating have been identified (McKnight et. al., 2002). Thus, it appears that ease of use may affect the trust of end users for a health information website.

While there is little research on the impact of credibility on trust of health information websites, credibility has been identified as important in online trust in general (Fogg et. al., 2001; Corritore et. al., 2003). Users' credibility assessments of health related websites seems to be focused on the nature and quality of the information (Stanford et. al., 2002). End-user perception of credibility also appears to be created through simultaneous evaluation of multiple sub-factors including expertise (Fogg \& Tseng, 1999), honesty (Fogg et al., 2001), reputation (Kim, Xu, \& Koh, 2004), and predictability (Barney \& Hansen, 1994). Sillence, et. al. (2004) found that once a website was chosen by a patient for further investigation, they switched from superficial elements of the website to a focus on expertise and honesty, looking for in-depth knowledge on a wide variety of relevant topics and clear, unbiased information. Likewise, other researchers have identified the importance of conveying expertise, providing comprehensive information, and projecting honesty and shared values between a website and a user as positive cues for trustworthiness (Fogg et. al., 2001).

Others have found reputation to be a key factor in the determination of the quality of health information websites by health care professionals and patients (Stanford, et. al., 2002). Stanford et. al. also noted that expert health information seekers focused on reputation, information source, and company motive when establishing credibility. The role of reputation has also been noted by online trust researchers examining nonhealth information websites (Einwiller, 2003; McKnight et. al., 2002; Kim et. al., 2004). For example, Kim et. al. found that reputation significantly impacted early and 
ongoing trust of consumers for online vendors, and explained 52 percent of the variance measured.

The role of predictability is less clear-cut. Early trust researchers found predictability (ie. a trustor's expectation that an object of trust will act consistently based on past experience) to be a consistent factor affecting trust (Barney \& Hansen, 1994). Consequently, predictability as a dimension of online trust has been discussed in contemporary research (McKnight et. al., 2002), although most online trust researchers have not measured it in their studies.

Risk has also been shown to have a strong relationship with trust by offline trust researchers (Luhmann, 1988), who maintains that there is no need for trust if there is no risk in a given situation. While there has been limited examination of the role of risk in online trust, a relationship between online trust and risk has been identified for transactional websites (Jarvenpaa et. al., 2000) McKnight et. al. (2002) identified "perceived web risk" as indirectly impacting user trust of a website, and found that a perception of high risk (of the general Internet environment) did reduce trust in a particular online vendor with relation to behavioral intent to transact with the vendor. Likewise, Einwiller (2003) studied risk as an antecedent to trust in online shopping and found that assessment of vendor risk most strongly impacted the development of a trusting intention [to act].

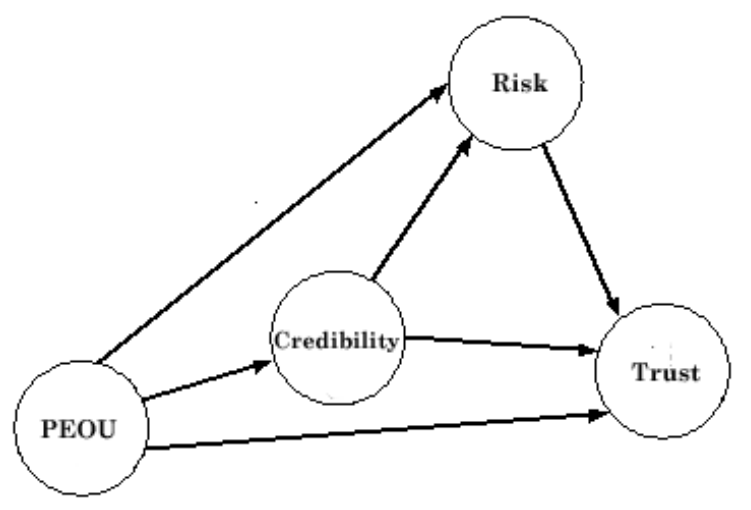

Figure 1. Proposed Model of Online Trust

We identified three perceived factors that may impact trust: credibility, ease of use and risk (see Figure 1). Credibility and ease of use are expected to positively affect trust, while risk is expected to have a reverse effect on trust. We view credibility as a multi-dimensional concept with four components: honesty, expertise, reputation, and predictability. Finally, we anticipate that ease of use will positively affect credibility, although this relationship has not been experimentally shown in the literature. However, we included the relationship because it could have strong implications for website design and is reasonable to think that a user who finds a website easy to use will tend to have a more positive perception of that website and its credibility. Similarly, we propose a relationship between ease of use and risk. That is, if a website is hard to use, a user may perceive it as risky.
Again, there is no research specifically examining this relationship, but is interesting to study as it would have implications for website design. We also hypothesize an inverse relationship between credibility and risk. That is, a website perceived as credible would be perceived as low risk. This relationship has also not been reported in the online trust literature, but is reasonable to propose and study.

\section{METHODOLOGY}

The participants were 176 well young adults, who were undergraduate and graduate students at a medium-sized university in the United States. The participants were regular computer users. The website chosen for use in the study was WebMD (http://www.webmd.com), because it is a well-known health information site, provides access to health wellness information (one of its four goals), was the only website specifically named as a primary source of online health information by users (Madden \& Fox, 2006). The research instrument was a 34 -item Likert-scale developed to measure online trust of websites. Twentyeight of the items were adapted from existing validated research tools with superficial adjustments and six items were new. The instrument was originally field tested and refined and later tested again and further refined to evaluate reliability and validity. The resulting set of items was streamlined to 4-5 items per concept, in order to keep the number of items per construct consistent with the tool used to measure Perceived Ease of Use (Davis et. al., 1989). The study was carried out in five large group, 40 minute sessions, in which each participant worked independently using the research materials which were embedded in a website. After providing demographic data, participants carried out three tasks on WebMD, one at a time. The tasks were designed to provide them with similar experiences and exposure to the WebMD website. No data were collected during the tasks since they were used strictly as an exercise to help participants focus and interact with the WebMD website. After interacting with the WebMD website through the tasks, participants filled out the 34-item instrument.

\section{INSTRUMENT VALIDATION}

Following usual validation procedures, a principal component factor analysis (PCA) was carried out first, followed by a confirmatory factor analysis (CFA). A PCA was conducted to determine the degree to which the factors predicted in our model (Figure 1) are actually represented in the data and to what extent the items loaded on the factors that we intended. Six factors emerged from the factor analysis, with all 34 items loading strongly (above 0.5) on at least one factor. Cronbach's reliability statistics showed that all had high internal consistency, with reliabilities ranging from 0.796 to 0.964 . It is noteworthy that the expertise items all loaded with the honesty construct, indicating that our participants did not perceive a distinction between the two concepts. Also, two reputation items, in addition to loading strongly with other reputation items, also loaded 
with the honesty grouping, suggesting a cross-correlation. One predictability item cross-loaded on two factors, showing a stronger factor loading with perceived ease of use (PEOU) items than predictability items. Similarly, two trust items loaded more strongly on the honesty subfactor than the trust construct. In sum, the strong factor loadings of all 34 items show the efficacy of these items in representing the concepts under study here. In terms of discriminant validity, the results showed that there were six distinct factors, which included three credibility subfactors.

CFA was then used to measure the unidimensionality of the model factors, or degree to which the model's items loaded only on their principle factors without exhibiting cross-correlational patterns with other factors. Following a standard approach to CFA, our postulated model, consisting of the four sub-factors of credibility, ease of use, risk and trust, was evaluated using AMOS 5.0 (see Table 1). The item groupings for the model's four factors were determined using the results of the PCA. The fourfactor model resulting from the CFA contained 15 items, subsumed under the factors of credibility, PEOU, risk, and trust. The credibility factor consisted of five items, all related to honesty and expertise. Predictability and reputation items, hypothesized as sub-factors of credibility, were eliminated by the CFA. As a result, the PEOU factor included all four of the original ease of use items, the risk factor consisted of four items, and the trust factor consisted of two items. The factor loadings ranged from 0.663 to 0.958 ; the reliability of the factors ranged from 0.889 to 0.964 . Note that for the chi-squared measure a non-significant result represents a desired adequate fit. In our case, the chi-squared value shows significance, which is undesirable, but it is well known that this often occurs if the sample has fewer than 200 participants (Segars, 1997). In this case, the statistic of chi-squared divided by degrees of freedom was used to assess our model fit. The result was 1.35 , well below the critical threshold of three. The other model fit measures (GFI, AGFI, CFI, NFI, and RMR) were also well within their recommended values. The result of the CFA is a more consistent and parsimonious instrument. It appears that the resulting 15-item instrument represents a good measurement model for the four main concepts of interest in this study: credibility, PEOU, risk, and trust.

\section{Discussion of Validation}

While the instrument administered to our sample of participants after their use of the WebMd site had high reliability, some of the factor loadings in the PCA exhibited cross-loadings, which pointed to a lack of unidimensionality in the items. However, the most interesting outcomes in the PCA were those related to honesty and expertise. The four items designed to measure expertise all loaded with the honesty sub-factor. The expertise items were meant to draw out beliefs about the competency reflected in the content of the health care information on the site; the items used words such as "knowledge," “competency," "expertise," and "qualified." However, the participants appeared to consider them equivalent to the honesty items which focused on integrity, truthfulness, believability, and dependability of information. In hindsight, we conclude that participants viewed content expertise, or the lack thereof, as an issue of honesty. That is, if the website content does not display expert knowledge in the critical area of health care information, then it is, in effect, not just lacking expertise but also honesty and truthfulness.

\begin{tabular}{|lc|}
\hline Model fit measure & $\begin{array}{l}\text { Values } \\
(\mathrm{p}=0.018, \\
\mathrm{df}=84)\end{array}$ \\
& 113.344 \\
Chi-Square & 1.350 \\
Chi-Square/df & 0.924 \\
Goodness of Fit Index (GFI) & 0.891 \\
Adjusted Goodness of Fit Index (AGFI) & 0.987 \\
Comparative Fit Index (CFI) & 0.953 \\
Normed Fit Index (NFI) & 0.032 \\
Root Mean Square Residual (RMR) & \\
\hline
\end{tabular}

Table 1: Confirmatory Factor Analysis Four Factors Model

It is notable in the credibility results that the items that remained consisted of honesty and expertise items, confirming that participants viewed these concepts as one. The predictability sub-factor fell out first in the CFA; we speculate that predictability may be a lower priority for participants compared to other credibility sub-factors, and indeed may have been seen in some cases as an issue of ease of use, e.g., item 15 . The reputation items also were eliminated in the CFA. Reputation might not have contributed to the credibility factor for two reasons. First, the participants might not have known the reputation of the WebMD website. Second, the participants were well educated and highly experienced web users, who might have felt competent to evaluate a website without resorting to reputation.

The discussion above suggests that the participants evaluated WebMD's credibility essentially from the viewpoint of its honesty and expertise and that they did not distinguish the two. It may be the case that the subfactors we included vary in importance in different domains or in the confidence of individuals to evaluate a website using their own criteria. That is, the individual may feel capable of evaluating information or a product, given honest, expert information about it, even if the provider's reputation is not previously known to the individual. This may be particularly true for a general health information website such as WebMD in contrast with a transactional website that involves products and market branding.

\section{ONLINE TRUST MODEL RESULTS}

The model was evaluated using SEM (see Table 2). All of the hypothesized paths were significant below the 


\begin{tabular}{|c|c|c|}
\hline Path & $\begin{array}{l}\text { Critical } \\
\text { ratio }(\mathrm{z})\end{array}$ & $\mathrm{p}$ \\
\hline PEOU $\rightarrow$ Credibility $\quad\left(\mathrm{R}^{2}=0.133\right)$ & 4.73 & 0.00 \\
\hline Credibility $\rightarrow$ Risk & -5.82 & 0.00 \\
\hline PEOU $\rightarrow$ Risk & -0.58 & 0.56 \\
\hline PEOU $\rightarrow$ Trust & 5.59 & 0.00 \\
\hline Credibility $\rightarrow$ Trust & 8.73 & 0.00 \\
\hline Risk $\rightarrow$ Trust & -4.31 & 0.00 \\
\hline Model fit measure & \multicolumn{2}{|c|}{$\begin{array}{l}\text { Values } \\
(\mathrm{p}=0.018, \mathrm{df}=84)\end{array}$} \\
\hline Chi-Square & \multicolumn{2}{|l|}{113.344} \\
\hline Chi-Square/df & \multicolumn{2}{|l|}{1.349} \\
\hline Goodness of Fit Index (GFI) & \multicolumn{2}{|l|}{0.924} \\
\hline Ad. Goodness of Fit Index (AGFI) & \multicolumn{2}{|l|}{0.891} \\
\hline Comparative Fit Index (CFI) & \multicolumn{2}{|l|}{0.987} \\
\hline Normed Fit Index (NFI) & \multicolumn{2}{|l|}{0.953} \\
\hline Root Mean Square Residual (RMR) & \multicolumn{2}{|l|}{0.032} \\
\hline
\end{tabular}

Table 2: Results of Path Analysis for the Online Trust Model

0.001 level, except for the path from PEOU to risk which was non-significant $(\mathrm{p}<.563)$. The $\mathrm{R}^{2}$ value of the trust is a high 0.73 , indicating that PEOU, credibility, and risk explained $73 \%$ of its variance. The fit statistics indicate a very good fit to the data. Using chi-squared again for fit, the result is well below the critical threshold of three. In addition, all the other model fit measures (GFI, AGFI, CFI, NFI, RMR) are within recommended values. Given the non-significant path from PEOU to risk, we dropped that path from the model and re-ran the analyses. The fit statistics for the final model were essentially identical to Table 2 (see Figure 2), with the results remain highly congruent when the path from PEOU to risk is removed.

\section{Discussion of the Analysis of the Online Trust Model}

The analysis of the WebMD data confirmed all of the predictive relationships of PEOU to risk. Credibility had a significant positive relationship to trust and a significant negative relationship to risk. Risk had a significant negative relationship to trust. Low credibility increases the user's perception of the level of risk of the website, while inversely high credibility is associated with low perceptions of risk. According to our results, if the user finds the honesty and expertise of the website to be positive, that supports the website's credibility, reduces the perception of risk, and ultimately increases the user's trust in the site. Credibility is important in a website such as WebMD, whose product is largely information meant to support users' health care decisions. Without credibility, there is little to be gained from such a health care website. In the worst case, a health care informational website that provides reliable, expert information, but nevertheless is perceived as lacking credibility, could cause actual harm to users by their failing to act on information provided by the website. This suggests that informational health care websites need to

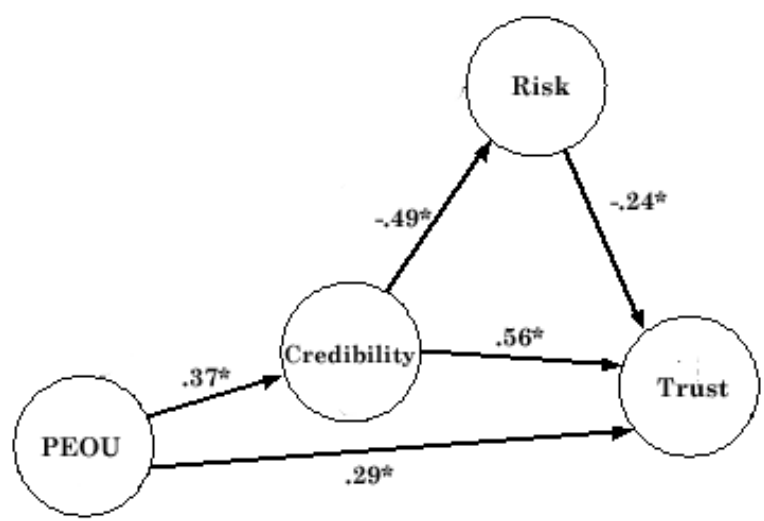

Figure 2. Path Analysis of the Final Online Trust Model of Health Information Websites $(* p<.001)$.

pay careful attention to their credibility cues. Such cues on the WebMD site include the awards page, which lists numerous honors and recognitions of WebMD from the press and health care organizations and societies, as well as biographies and photos of the senior medical staff and medical writers, as well as an independent medical review board page, which states that its role is "to ensure that WebMD meets high standards." These cues are meant to strengthen the users' awareness of the website's expertise and so credibility.

We expected that PEOU would directly affect trust, credibility, and risk, as well as affecting trust indirectly through the mediation of credibility and risk. PEOU did indeed have a significant positive direct relationship to trust, indicating that users consider ease of use an important consideration in deciding whether to trust a health care website. As predicted, PEOU also had a significant positive relationship with credibility, confirming that users' perceptions of the usability of the website affect their judgments of credibility. It is important to realize that users' perceptions of the credibility of the website are augmented by cues about its ease of use. A poorly organized, difficult to use website may be perceived as a sign that the credibility of the website's information is poor.

Supporting the importance of perceived ease of use on users' perception of credibility, Sillence et al. (2004) report that users of health care websites make initial decisions about whether to use a website based largely on usability factors such as ease of use. Then patients made a second stage decision based on the actual informational contents of the site, i.e., the credibility of the site. This is consistent with our findings in which PEOU's effect on trust is mediated by credibility. Although Sillence et al. observed the stages of initial use and acceptance over a period of weeks, our results from one-time use of WebMD suggest that the stages of initial use and user acceptance of a website can occur rapidly during a single session on a website, if the user carries out meaningful tasks. 
In our model, low PEOU was hypothesized to be associated with high risk. This prediction was based on the premise that poor website ease of use would be a sign to users that the website was risky. However, the results did not support a direct relationship between PEOU and risk. Essentially, poor ease of use did not directly affect users' beliefs about the website's risk. However, PEOU does have an indirect relationship with risk through credibility, that is, low PEOU is associated with low credibility, and low credibility is associated with high risk. Thus, the effect of PEOU on risk is mediated by credibility. While we had expected a direct relationship between PEOU and risk, the failure to find that relationship may be related to the informational focus of the website. Perhaps a direct association between ease of use and risk might be identified with transactional websites.

\section{CONCLUSIONS}

The contribution of this research is three-fold. First, we have taken the approach that an understanding of the nature of online trust in well health information websites must be grounded in the broader question of online health information user trust rather than piecemeal explorations of specific elements of health information website trustworthiness. Ultimately, this approach has the greatest potential to lead to general design guidelines to direct the development of health care websites that engender trust. Second, this research provides a validated instrument for measuring online trust of health care websites. Third, the results support a model of online trust for well health websites, emphasizing the importance of credibility, ease of use, and risk in users' trust of well health websites.

Limitations include the use of a single health care website. In order to generalize, the same experiment should be replicated using other health websites. Second, we used students to represent the general well-adult population. This is a more limited group than the general population. Future indicated implications include replicating the study with individuals who have real health concerns. Another would be to study senior citizens or economically disadvantaged, who are often financially constrained from using the traditional health care system and have more chronic health problems. Finally, studies to identify designs that impact credibility, risk, and PEOU in order to engender trust of health websites could impact patient compliance.

\section{REFERENCES}

1. Barney, J. \& Hansen, M. (1994). Trustworthiness as a source of competitive advantage. Strategic Management Journal, 15, 175-190

2. Corritore C, Kracher B, \& Wiedenbeck S. (2003). On-line trust: Concepts, evolving themes, a model. International Journal of Human Computer Studies, 58, 737-58.
3. Einwiller, S. (2003). When reputation engenders trust: An empirical investigation in business-toconsumer electronic commerce. Electronic Markets, 13(3), 196-209.

4. Fogg, F., Soohoo, C., Danielson, D., Marable, L., Stanford, J., \& Tauber, E. (2003). How do users evaluate the credibility of web sites? A study with over 2,500 participants. Proceedings of the 2003 Conference on Designing for User Experiences. New York: ACM Press.

5. Fogg B., \& Tseng H. (1999). The elements of computer credibility. Proceedings of the Conference on Human Factors in Computing Systems CHI 1999, New York: ACM Press.

6. Gefen, D. \& Straub, D. (2003). Managing user trust in B2C e-Services. e-Service Journal, 2(2), 7-24.

7. Jarvenpaa, S. Tractinsky, N., \& Vitale, M. (2000). Consumer trust in an Internet store. Information Technology Management, 1(1-2), 45-71.

8. Kim, H., Xu, Y., \& Koh, J. (2004). A comparison of online trust building factors between potential customers and repeat customers. Journal of the Association for Information Systems, 5(10), 392-420.

9. Luhmann, N. (1988). Familiarity, confidence, trust: problems and alternatives. In D. Gambetta (Ed.), Trust: Making and Breaking Cooperative Relations (pp. 94-107). New York: Basil Blackwell.

10. Madden, M. \& Fox, S. (2006). Finding answers online in sickness and in health. In Pew Internet \& American Life Project Report, 7.22.07. http://www.pewinternet.org/PPF/r/183/report_display asp.

11. McKnight, D., Choudhury, V., \& Kacmar, C. (2002a). The impact of initial consumer trust on intentions to transact with a web site: A trust building model. Journal of Strategic Information Systems, 11, 297-323.

12. Segars, A. (1997). Assessing the unidimensionality of measurement: a paradigm and illustration within the context of information systems research. Omega, 25(1), 107-21.

13. Sillence E., Briggs P., Fishwick L., \& Harris P. (2004). Trust and mistrust of online health sites. Proceedings of the Conference on Human Factors in Computing Systems CHI 2004. New York: ACM Press.

14. Stanford, J., Tauber, E., Fogg, B., \& Marable, L. (2002). Experts vs. online consumers: A comparative credibility study of health and finance Web sites. Consumer WebWatch Research Report, 5/6/07. http://www.consumerwebwatch.org/dynamic/webcredibility-reports-experts-vs-online-abstract.cfm, 